\title{
Original
}

\section{Effects of the Lathyrogen, $\beta$-aminopropionitrile on Rats with Adriamycin Nephropathy}

\author{
Yan Liu ${ }^{1,2)}$, Ashio Yoshimura ${ }^{1)}$, Kiyoko InUi ${ }^{1)}$, \\ Xiaoshi ZhONG $^{1,2)}$, Susumu Watanabe ${ }^{1)}$, Hiroyuki Morita ${ }^{1)}$, \\ and Terukuni IDEURA ${ }^{1)}$
}

\begin{abstract}
It has been reported that the lathyrogen, $\beta$-aminopropionitrile ( $\beta$ APN), is an irreversible inhibitor of lysyl oxidase, an extracellular enzyme that promotes crosslink formation of both collagen and elastin. This study was designed to assess the potential therapeutic effects of $\beta$-APN on experimental glomerulosclerosis in Sprague-Dawley rats induced by Adriamycin (ADR). Rats with ADR-induced nephropathy were divided into two groups, $\beta$-APN treated $(n=11)$ and vehicle-only treated controls $(n=11)$. Urine protein increased 2 weeks after the first injection of ADR in all rats. There was no difference in urine protein levels between the two groups at 4 weeks, however at 8 weeks post-ADR injection, it was significantly higher ( 4 fold) in the control group compared to the $\beta$-APN treated group $(\mathrm{p}<0.01)$. Albuminuria increased continually after ADR injection in all rats. Blood urea nitrogen (BUN) increased from week 4 in all rats, but the levels were suppressed in the $\beta$-APN treated group when compared to the control group at both week 4 and $8 \quad(\mathrm{p}<0.05)$. Pathological studies showed that the development of glomerulosclerosis and collagen IV deposition in glomeruli were significantly suppressed in the $\beta$-APN treated group compared to the control. In conclusion, $\beta$-APN may act as a potential protective agent through inhibiting collagen cross-linking and suppressing the progression of glomerulosclerosis.
\end{abstract}

Key words : adriamycin nephropathy, lysyl oxidase, $\beta$-aminopropionitrile, fibrosis, urine protein

\section{Introduction}

Renal fibrosis is the final event in a complex pathogenetic cascade originating from immunologic, toxic or infective renal injuries ${ }^{1-4)}$, and is characterized by the abnormal deposition of numerous extracellular matrix (ECM) proteins in glomeruli and interstitium. Therefore, suppression of renal fibrosis is a critical treatment strategy in progressive renal diseases. Type IV collagen accumulation in glomeruli can lead to glomerulosclerosis, while type I and type III collagens bring about interstitial fibrosis. Although the mechanisms of the early stage of renal damage, in which renal cells are stimulated to produce collagen components is understood ${ }^{5,6)}$, very little is known about the progressive processes of the

\footnotetext{
${ }^{1)}$ Department of Medicine, Division of Nephrology, Showa University Fujigaoka Hospital, 1-30 Fujigaoka, Aoba-ku, Yokohama 227-8501, Japan.

${ }^{2)}$ Department of Medicine, Division of Nephrology, Guangzhou Red-Cross Hospital, Guangzhou, P. R. China ${ }^{+}$.
} 
developed renal disease involving collagen metabolism. Lysyl oxidase (LOX), an extracellular enzyme, can promote collagen and elastin cross-linking formation ${ }^{7)}$, resulting in stable and insoluble collagen molecules ${ }^{8)}$. Recent studies have demonstrated that LOX-induced collagen crosslink formation plays a key role in the development of tissue fibrosis in human organs $^{7,9-11)}$ as well as in experimental glomerulosclerosis in the rat ${ }^{12)}$. In addition, we have reported that LOX mRNA expression is increased in mesangial proliferative nephritis in the rat $^{13)}$. Beta-aminopropionitrile ( $\beta$-APN), an irreversible inhibitor of LOX, can suppress the cross-linking formation of collagen and elastin in experimental animal studies, ${ }^{54}$ and prevent tissue fibrosis in several organs, such as lung, vessels, skin scar and bone ${ }^{9-11)}$. This study was designed to investigate whether the inhibition of collagen cross-linking by $\beta$ APN may be beneficial in the suppression of the development of glomerulosclerosis in rats.

\section{Material and Methods}

\section{Experimental design and disease model}

Twenty-two male Sprague-Dawley rats weighing 180-200 g (Nippon Ikagakyu Doubutsu, Tokyo, Japan) were given two doses $(2 \mathrm{mg} / \mathrm{kg}$ ) of Adriamycin (ADR, Sigma, St. Louis, MO, USA): the first on day 1 , and the 2 nd on day 14 as reported previously ${ }^{15)}$. The ADR was dissolved in $0.5 \mathrm{ml}$ sterile physiologic saline and infused slowly into the tail vein. After the first injection of ADR, the rats were assigned either to a treatment group $(n=11)$, which received $\beta$-APN (Tokyo Kasei, Tokyo, Japan) $300 \mathrm{mg} / \mathrm{kg}$, body weight/day by gastric tube for 8 weeks, or a control group $(n=11)$, which received only saline by the same manner. The rats were maintained on standard food and were allowed free access to water. All of the experimental procedures were approved by the Institutional Animal Care and Use Committee of Showa University and were performed in accordance with the criteria outlined in the "Guide for the Care and Use of Laboratory Animals" prepared by the National Academy of Science. Urinary protein excretion per twenty-four hours was examined at 0 , 2, 4 and 8 weeks after disease induction. Rats were sacrificed at $4(n=5)$ and 8 weeks $(n=6)$ after collecting blood samples to measure the total protein, albumin and blood urea nitrogen (BUN). In each group, the kidneys were removed for histological examination.

\section{Renal morphology and glomerulosclerosis index}

Kidney tissues from all rats were fixed in buffered formalin or methyl Carnoy's solution and embedded in paraffin before examination by light microscopy or immunoperoxidase staining respectively. Four-micrometer sections of buffered formalin-fixed tissues were stained with PAS (periodic acid-Schiff) or PAM (periodic acid-methenamine-silver) reagent and counterstained with hematoxylin ${ }^{4)}$.

Glomerulosclerosis was evaluated in the PAM-stained sections. The PAM-stained area in the glomeruli was measured quantitatively by a computer-aided manipulator (Mac Scope, version 2.5, Mitani Corp., Tokyo, Japan) with a Fuji digital camera system HC-2500 (Fuji Film, Tokyo, Japan). The whole glomerular area was measured by tracking out the glomerular tuft. The glomerulosclerosis index (\%) was expressed as the ratio of PAMpositive area in 20 randomly selected glomeruli.

\section{Immunostaining for type IV collagen and collagen IV score}

Kidney sections $(4 \mu \mathrm{m})$ fixed in methyl Carnoy's solution, were stained by the indirect 
immunoperoxidase method to determine the collagen IV score ${ }^{16)}$. The primary antibody used was the IgG fraction of polyclonal rabbit anti-mouse collagen IV (Collaborative Research, Bedford, MA). The collagen IV score was calculated by the same manner used for the evaluation for glomerulosclerosis using a computer-aided manipulator:

collagen $\mathrm{IV}$ score $(\%)=($ collagen $\mathrm{V}$-positive area/whole glomerular area $) \times 100$.

An equivalent concentration of an irrelevant murine monoclonal antibody was used as the negative control in this assay.

\section{Measurement of serum chemistry and urine protein excretion}

Blood samples were centrifuged and serum taken and stored at $-80^{\circ} \mathrm{C}$ until analysis. Total protein, albumin and BUN were determined using standard laboratory methods with an automated multi-parametric analyzer as previously reported ${ }^{16)}$. The amount of urine protein excreted was measured by a sulfosalicylic acid method ${ }^{17)}$ using a whole serum standard (Lab Trol, Dade Diagnostics, Aquado, Puerto Rico).

\section{Statistical analysis}

All values are expressed as mean \pm SD unless stated otherwise. Statistical significance (defined as $\mathrm{p}<0.05$ ) was evaluated using the $\mathrm{t}$ test $^{18}$ ).

\section{Results}

\section{Clinical outcomes}

As reported by other authors ${ }^{12)}$, who described this model of chronic renal disease, the rats in this study treated with ADR developed proteinuria of glomerular origin within 4 weeks which continued to increase until the day of nephrectomy at 8 weeks $(5.32 \pm 0.80$ $\mathrm{mg} /$ day at day $0,6.18 \pm 1.18 \mathrm{mg} /$ day at week $2,10.24 \pm 3.22 \mathrm{mg} /$ day at week 4 , and 40.15 $\pm 32.50 \mathrm{mg} /$ day at week 8 ). From day 0 to 4 weeks, there was no significant difference between urine protein excretions of $\beta$-APN treated and control group. However, treatment

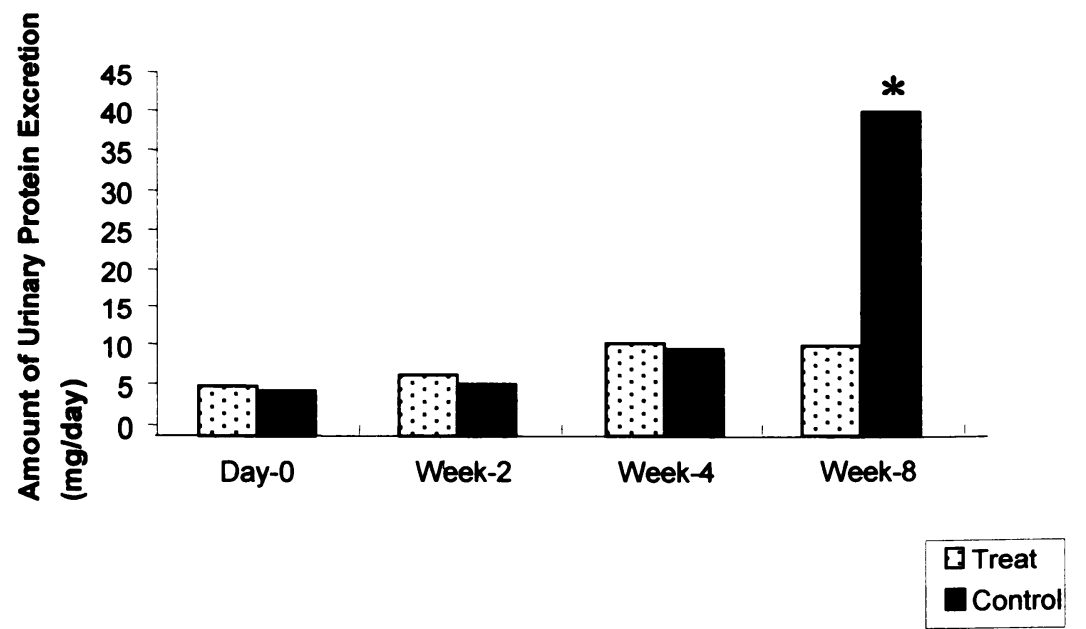

Fig. 1. Urinary protein excretion per day. Treatment with $\beta$-APN significantly reduced urinary protein excretion at 8 weeks after Adriamycin (ADR) nephropathy induction $\left(10.69 \pm 5.54 \mathrm{mg} / \mathrm{day}\right.$ vs $\left.40.15 \pm 32.50 \mathrm{mg} / \mathrm{day},{ }^{*} \mathrm{p}<0.01\right)$. Treat : $\beta-A P N-$ treated ADR nephropathy rats, Cont: Control ADR nephropathy rats. 
with $\beta$-APN significantly reduced urinary protein excretion at 8 weeks after disease induction $(10.69 \pm 5.54 \mathrm{mg} /$ day vs. $40.15 \pm 32.50 \mathrm{mg} /$ day, $\mathrm{p}<0.01)$ (Fig. 1).

There was no significant difference in serum concentration of total protein and albumin between the two groups at both 4 and 8 weeks after disease induction. (Table 1). The mean BUN concentrations in $\beta$-APN-treated group and control group at 4 and 8 weeks were $15.2 \pm 4.82$ vs $17.8 \pm 1.79 \mathrm{mg} / \mathrm{dl}$ and $17.4 \pm 1.14$ vs $18.6 \pm 3.78 \mathrm{mg} / \mathrm{dl}$ respectively. BetaAPN treatment significantly suppressed the increase in BUN levels at both 4 and 8 weeks after disease induction $(\mathbf{P}<0.05$ in each $)$.

Table 1. Blood analysis

\begin{tabular}{ccccccc}
\hline & \multicolumn{3}{c}{ week-4 } & \multicolumn{3}{c}{ week-8 } \\
\hline & $\mathrm{Tp}$ & $\mathrm{Alb}$ & $\mathrm{BUN}$ & $\mathrm{Tp}$ & $\mathrm{Alb}$ & BUN \\
\hline$\beta$-APN & $5.0 \pm 0.63$ & $3.0 \pm 0.41$ & $15.2 \pm 4.82^{*}$ & $5.5 \pm 0.16$ & $3.2 \pm 0.15$ & $17.4 \pm 1.14^{*}$ \\
Control & $5.5 \pm 0.26$ & $3.3 \pm 0.09$ & $17.8 \pm 0.12$ & $5.5 \pm 0.12$ & $3.2 \pm 0.11$ & $18.6 \pm 3.78$ \\
$\mathrm{P}$ value & $\mathrm{NS}$ & $\mathrm{NS}$ & $\mathrm{P}<0.05$ & $\mathrm{NS}$ & $\mathrm{NS}$ & $\mathrm{P}<0.05$ \\
\hline
\end{tabular}

$\beta$-APN : $\beta$-APN-treated rats, Control : control rats

Tp total protein, Alb albumin, BUN blood urea nitrogen,

${ }^{*} \mathrm{p}<0.05$, compared with the values of 4 -week

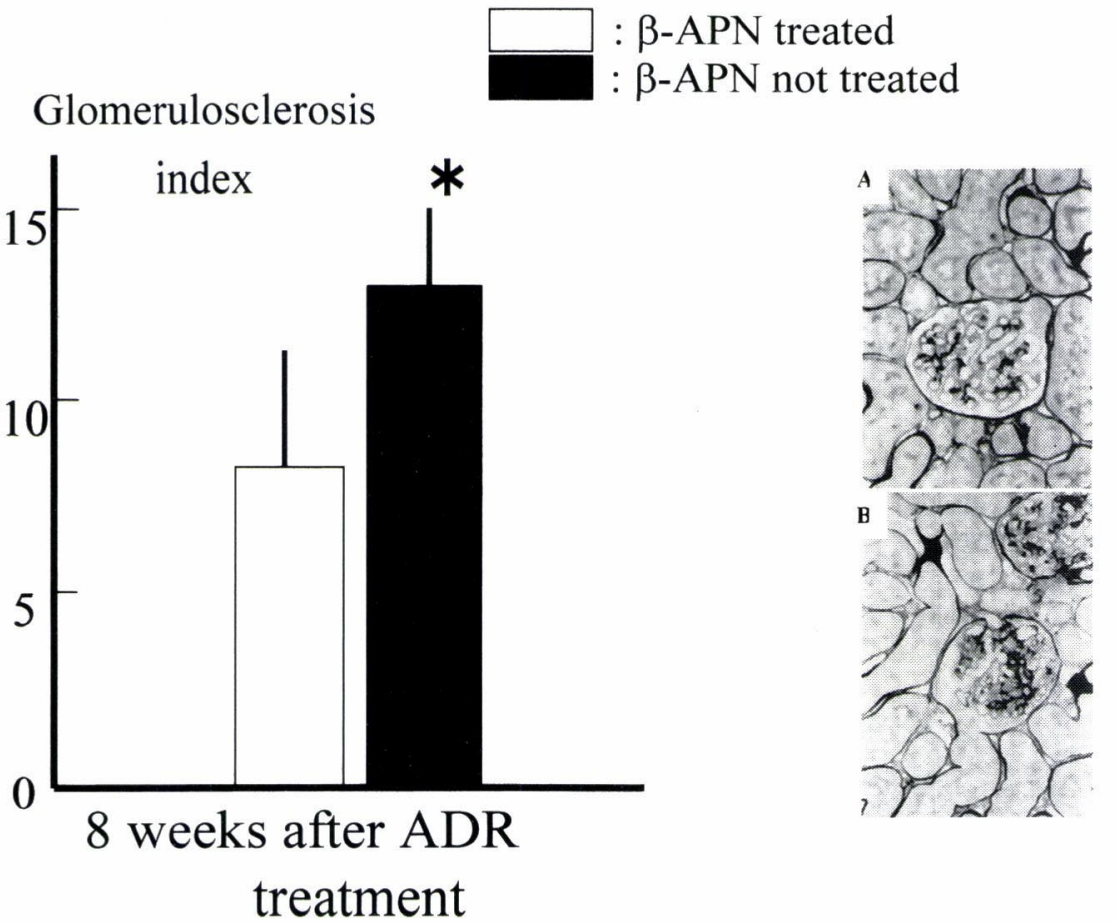

Fig. 2. Glomerulosclerosis index evaluated by Periodic acid-methenamine-silver-stained sections in $\beta$-APN treated (A) and control Adriamycin nephropathty rats (B). $\beta$-APN treatment significantly suppressed the development of glomerulosclerosis at 8 weeks after disease induction $\left({ }^{*} \mathrm{p}<0.01\right)$.

Periodic acid-methenamine-silver staining, $\times 400$ 


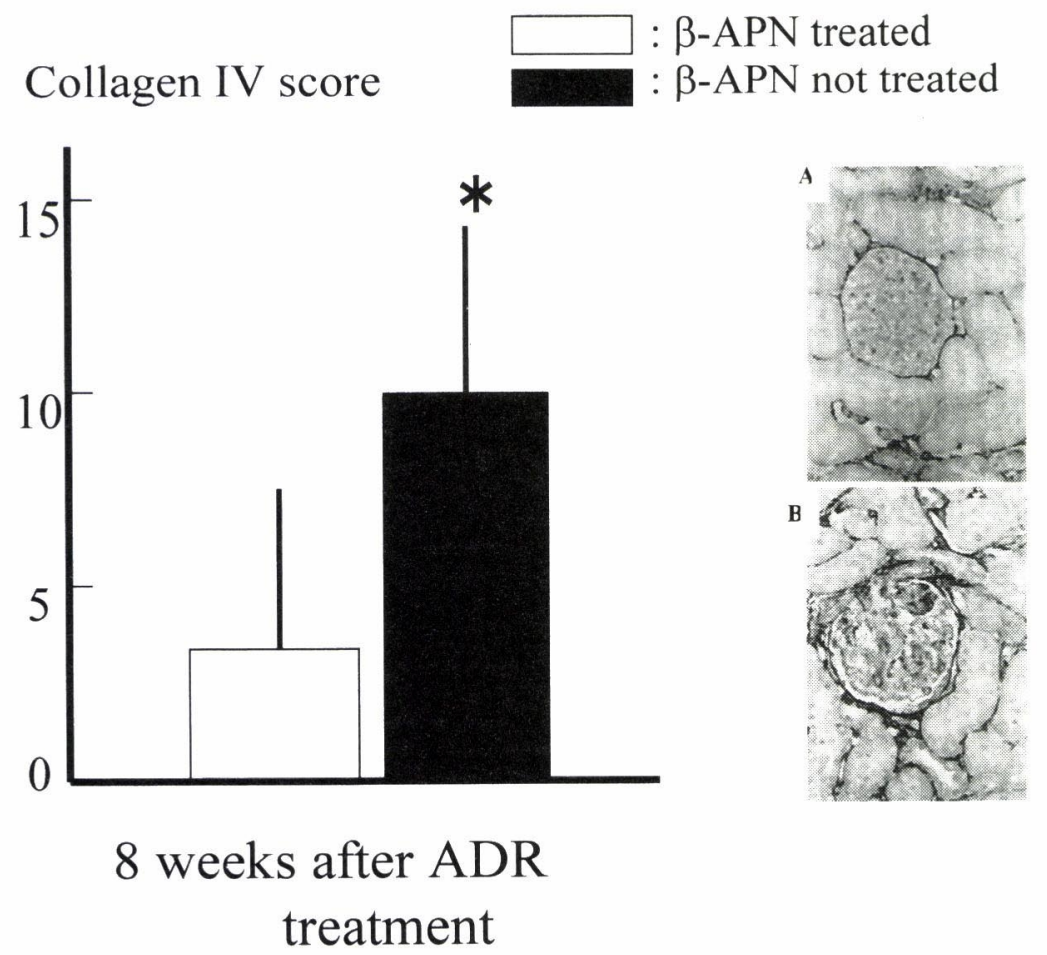

Fig. 3. Collagen IV score in $\beta$-APN treated (A) and control adriamycin nephropathty rats (B). $\beta$-APN treatment significantly suppressed glomerular collagen IV deposition in Adriamycin nephropathy at 8 weeks after disease induction $\left({ }^{*} \mathrm{p}<0.01\right)$. Indirect immunoperoxidase staining, $\times 400$

\section{Morphometric analysis}

The glomerulosclerosis index on PAM-stained sections was significantly lower in the $\beta$ APN-treated group 8 weeks after disease induction, at approximately $60 \%$ of that in the control rats $(p<0.01$, Fig. 2$)$. The collagen IV score was also significantly lower in the $\beta$-APN treated group at 8 weeks $(\mathrm{p}<0.01$, Fig. 3$)$. Thus, $\beta$-APN treatment suppressed the development of glomerulosclerosis and type IV collagen deposition in glomeruli in adriamycin nephropathy.

\section{Discussion}

The effect of LOX expression on collagen cross-linking formation during chronic adriamycin nephropathy was studied by Di Donato et $a l^{12)}$, who demonstrated that the increased expression of LOX mRNA in kidney tissue precedes the appearance of advanced renal fibrosis. We have already reported the increased expression of LOX mRNA in progressive mesangial proliferative nephritis in the rat ${ }^{13)}$. Mesangial cell proliferation and subsequent accumulation of ECM proteins are the major histological features of many progressive glomerular diseases. $\beta$-APN is an irreversible inhibitor of LOX and can suppress the formation of cross-linked collagen. Therefore early inhibition of LOX by $\beta$ APN may suppress the development of glomerulosclerosis. In the present study, $\beta$-APN 
treatment decreased urinary protein excretion and suppressed the development of glomerulosclerosis in rats with adriamycin nephropathy. Proteinuria is an independent risk factor in the progression of chronic renal disease either by primary glomerular damage or through a secondary mechanism, such as hypertension and hyperlipidemia ${ }^{19-21)}$. So the suppression of urine protein excretion by $\beta$-APN in this model implicates that this compound may represent a potential treatment in chronic renal disease. To our knowledge, this is the first report of the effect of $\beta$-APN in a chronic kidney diseased model. However, the mechanism of $\beta$-APN suppression on proteinuria was not determined. This suppressive effect appeared 4 weeks after adriamycin nephropathy induction, which corresponds with the peak expression of LOX mRNA in the kidney tissue in this model ${ }^{12}$. From these data, the suppressive effect of $\beta$-APN on proteinuria may be partly explained by its inhibition of LOX. The suppression of LOX by $\beta$-APN may also be beneficial in preventing the development of glomerulosclerosis by reducing collagen IV cross-linking and deposition. In conclusion, the inhibition of collagen cross-linking by $\beta$-APN may be a potential antifibrotic strategy in chronic disease.

\section{References}

1) Jones CL, Buch S, Post M, Mc Culloch L, Liu E and Eddy AA : Pathogenesis of interstitial fibrosis in chronic purine aminonucleoside nephrosis. Kidney Int $40: 1012-1031$ (1991)

2) Sharma AK, Mauer SM, Kim Y and Michael AF : Interstitial fibrosis in obstructive nephropathy. Kidney Int 44 : 774-788 (1993)

3) Yoshimura A, Iwasaki S, Inui $K$, Ideura T, Kashikawa S, Yanagisawa $M$ and Masaki $T$ : Endothelin-1 and endothelin B type receptor are induced in mesangial proliferative nephritis in the rat. Kidney Int 48 : 12901297 (1995)

4) Alpers CE, Hudkins KL, Gown AM and Johson RJ: Enhanced expression of "muscle-specific" actin in glomerulonephritis. Kidney Int 41 : 1134-1142 (1992)

5) Bohle A, Glamb D, Grund KE and MacKensen $S$ : Correlation between relative interstitial volume of the renal cortex and serum creatinine concentration in minimal changes with nephritic syndrome and in focal sclerosing glomerulonephritis. Virchows Arch A Pathol Anat Histol 376 : 221-232 (1977)

6) Martin JE, Sosa-Melgarejo JA, Swash M, Mather K, Leigh PM and Berry CL: Purkinje cell toxicity of $\beta$ aminopropionitrile in the rat. Virchows Arch A Pathol Anat Histol 419 : 403-408 (1991)

7) Tang SS, Trackman PC and Kagan HM : Reaction of aortic lysyl oxidase with beta-aminopropionitrile. J Biol Chem 258 : 4331-4338 (1983)

8) Pinnell SR and Martin GR: The cross-linking of collagen and elastin: enzymatic conversion of lysine in peptide linkage to $\alpha$-aminoadipic- $\delta$-semialdehyde (allysine) by an extract from bone. Proc Natl Acad Sci USA 61 : 708-716 (1968)

9) Riley DJ, Kerr JS, Berg RA, Ianni BD, Pietra GG, Edelman NH and Prockop DJ : Beta-aminopropionitrile prevents bleomycin-induced pulmonary fibrosis in the hamster. Am Rev Respir Dis 125 : 67-73 (1982)

10) Peacock EE Jr : Control of wound healing and scar formation in surgical patients. Arch Surg 116 : 1325-1329 (1981)

11) Sandhu HS and Jande SS : Effects of $\beta$-aminopropionitrile on formation and mineralization of rat bone matrix. Calcif Tissue Int 34 : 80-85 (1982)

12) Di Donato A, Ghiggeri GM, Di Duca M, Jivotenko E, Acinni R, Campolo J, Ginevri F and Gusmano R : Lysyl oxidase expression and collagen cross-linking during chronic adriamycin nephropathy. Nephron 76 : 192-200 (1997)

13) Liu Y, Yoshimura A, Inui K, Yokota N, Watanabe S, Morita H and Ideura T : Increased expression of lysyl oxidase mRNA in progressive mesangial proliferative nephritis in the rat. Showa Univ J Med Sci 12 : 219-225 (2000)

14) Moorehead LL, Smith J, Stewart $\mathbf{R}$ and Kimbrough $\mathbf{R}$ : Effects of Beta-aminopropionitrile after glaucoma filtration surgery: Pilot human trial. Ann Ophthalmol 19 : 223-225 (1987)

15) Okuda S, Oh T, Tsuruda H, Onoyoma K, Fujimi $S$ and Fujishima $M$ : Adriamycin-induced nephropathy as a model of chronic progressive glomerular disease. Kidney Int 29 : 502-510 (1986)

16) Yoshimura A, Inui K, Nemoto T, Uda S, Sugenoya Y, Watanabe S, Yokota N, Taira T, Iwasaki S and Ideura 
T: Sinvastatin suppresses glomerular cell proliferation and macrophage infiltration in rats with mesangial proliferative nephritis. J Am Soc Nephrol 9 : 2027-2039 (1998)

17) Bradley GM and Benson ES : Examination of the urine. In: Todd-Sanford Clinical Diagnosis by Laboratory Methods, 15th ed, Davidson I and Henry JB(Eds), Philadelphia, Saunders, pp. 74-104 (1974)

18) Wallenstein S, Zucker $\mathrm{CL}$ and Fleiss JL: Some statistical methods useful in circulation research. Circ Res $47: 1-9(1980)$

19) Abbate M and Remuzzi G : Proteinuria as a mediator of tubulointerstitial injury. Kidney Blood Press Res 22 : 37-46 (1999)

20) Cameron JS : Proteinuria and progression in human glomerular diseases. Am J Nephrol 10 Suppl 1 : 81-87 (1990)

21) de Boer E, Navis G, Wapstra FH, de Jong PE and de Zeeuw D : Effect of proteinuria reduction of prevention of focal glomerulosclerosis by angiotensin-converting enzyme inhibition is modifiable. Kidney Int Suppl 71 : S42-S46 (1999)

[Received June 9, 2003 : Accepted July 18, 2003] 